\title{
Understanding the Effect of Social Media Overload on Academic Performance: A Stressor-Strain-Outcome Perspective
}

\author{
Lingling $\mathrm{Yu}^{*}$ \\ School of Management \\ University of Science and \\ Technology of China \\ lingyu17@mail.ustc.edu.cn
}

\author{
Chenling Shi \\ School of Management \\ University of Science and \\ Technology of China \\ shic1460@mail.ustc.edu.cn
}

\author{
Xiongfei Cao \\ School of Management \\ Hefei University of Technology \\ caoxf312@126.com
}

\begin{abstract}
Social media has deeply penetrated into university students' daily lives, inducing excessive usage that can result in social media overload. However, only few studies have explored the adverse consequences of social media use from a pedagogical perspective. This paper aims to investigate the effects of overload on students' academic performance and the underlying mechanism. Based on the stressor-strain-outcome model, we propose that information, communication, and social overloads influence technostress and exhaustion of students, which in turn impair their academic performance. Results from a study of 249 Chinese social media users in universities reveal that all three types of overload enhance technostress, but only information overload significantly affect exhaustion. Both technostress and exhaustion have negative effects on academic performance. This study enriches social media literature by identifying a more comprehensive classification of social media-related overload among university students and investigating the exact mechanism of excessive social media use in educational environment.
\end{abstract}

\section{Introduction}

With the rapid expansion of social media use in the past few years, the dark side of social media has emerged and become evident. The penetration of mobile devices and various social media applications allow people to contact with each other anytime and anywhere. This pervasive nature may result in excessive usage, which can exert negative outcomes on both individuals and organizations. For instance, some users spend all day on Facebook to check news feed and update information

\footnotetext{
* Corresponding author
}

while walking, relaxing, or learning, as seen in case of Facebook addiction [1].

The person-environment (P-E) fit model has recognized a phenomenon termed as overload to represent individual's unbalanced state of being over-stimulated by the requests from the environment [2]. With widespread access, social media users are forced to spend considerable effort on information processing and social interaction. Spending such huge amounts of time and energy on social media can lead to the phenomenon called overload, which may eventually induce physical and mental burden and strain [3]. Currently, it is common to observe the phenomenon of overload among a large number of social media users. Although university students occupy a large proportion of participants in social media use, and their lifestyle has been deeply affected by social media, its influencing mechanism on students is yet to be explored in the education literature and information systems (IS) research. Previous research has pointed out the benefits of using social media for students, such as attaining social acceptance, cultivating social capital, as well as enhancing learning outcomes [4]. However, it is notable that the use of information technology (IT) will cause disturbing behavioral and psychological issues (i.e., depression, anxiety, and productivity loss) when it surpasses the optimal level [5] and overload has been recognized as a significant factor for inducing these problems [6]. Currently, the dark side of IT overload in the workplace has been explored in different investigations, such as leading to higher work pressures, poor work performance, and job burnout [7], but the focus is mainly on the business environment. Given that students are one of the most active groups in social media platforms, developing instrument models to measure the potential negative consequences of social media use on university students is of great importance.

The purpose of this study is to investigate the mechanism of negative social media effects on 
university students. We begin our study by asking the following research question: How does social media overload affect university students' academic performance? Drawing upon the stressor-strain-outcome (S-S-O) model, we propose that information, communication, and social overloads serve as stressors that induce students' internal strain states (i.e., technostress and exhaustion). The change of students' internal strain states then further impairs their academic performance.

The contributions of our study lie in the following aspects. First, this study enriches social media literature by investigating the negative impacts of social media use in educational environment. We explore the adverse consequences of excessive social media usage among university students and examine the effect of overload on their academic performance. Second, this study extends the overload research by identifying a more comprehensive classification of social media-related overload in educational context, namely, information overload, communication overload, and social overload. It advances our understanding of irrational usage of social media in school environment and emphasizes the existence of social overload in excessive social media use among university students.

\section{Theoretical background}

\subsection{S-S-O model}

The S-S-O model proposed by [8] reveals that stressors can cause strain, which in turn induce negative consequences. According to the S-S-O model, stressors are defined as environmental stimuli that are perceived by individuals as irritating, troublesome, or disruptive. Common stressors include overload, conflict and invasion [9-11]. Strain refers to the psychological reaction of individuals to stressors, and produces a disruptive impact on individuals' concentration, physiology, and emotion [12]. Strain such as emotional exhaustion and fatigue are most widely studied in IT research [13-15]. In the organizational environment, stressors are the conditions of factors that create stress, and strain is the psychological outcome of stress. Moreover, strain mediates the effect of perceived stressors on outcome variables [8]. Previous stress-related research has viewed reduced organizational commitment, poor job performance, and discontinuous intention as consequences of strain [14, $16,17]$.

A number of studies have examined the S-S-O model in stress-related research. For example, [12] investigated how work stressors, including work characteristics and emotional dissonance, affected the work strain of employees' subjective health and job outcomes. [13] found that customer-related social stressors positively influenced emotional exhaustion, which in turn negatively affected customer orientation and service recovery performance. However, these studies mainly focused on the work stress in the workplace context. As the widespread use of social media among university students, they are more likely to spend much time on social media resulting in excessive usage associated with technostress, which can incur negative academic consequences. The investigation of S-S-O model on the technostress research in the educational environment has seldom been examined. Therefore, we adopt the S-S-O model as the theoretical foundation to explore the negative consequences of social media overload on university students' academic performance.

\subsection{Overload as stressor}

Despite of the fact that social media can be beneficial to students for friendship, social well-being, and knowledge exchange, negative results can appear when it exceeds the available resources and energy of an individual [5]. In social media context, overload is a critical factor in inducing negative outcomes [3]. According to the person-environment fit perspective, overload derives from the disequilibrium between the unexpected amount of demands in the environment and individual's limited handling ability [2]. In the present study, overload refers to an extensive burdened state caused by a great number of stimuli in social media use, which is uncomfortable for an individual to cope with.

As a representative stressor, overload has been studied widely in different research areas, such as work overload [9], connection overload [18], as well as social overload [14]. In IT research, the phenomenon of technology overload has been investigated by many scholars. Technology overload can be divided into three dimensions: information overload, communication overload, and system feature overload [5]. Information overload results from the overwhelming amount of information on social media that is beyond individual's processing ability, especially when the information is presented in a too fast and non-sequential way. Communication overload refers to the condition that individuals' communication skills are challenged due to too many communication demands embedded in social media. System feature overload represents the technology complexity originated from the technology or the system itself. Considering that young users have a stronger acceptance of new technology updates, technological problems are not likely to occur among 
young adult users in the use of social media [19]. Therefore, system feature overload has become less of a problem for university students in this study.

In the social media context, information overload stresses more on processing a considerable amount of information that individuals seek via social media, while communication overload is associated with the interruption and frequent unplanned communication requirements initiated by others. Specifically, the younger generation like university students are the major participants of various social activities on social media platforms [20], with strong needs for socializing. Since the relationships embedded in the social network tend to be reciprocal, individuals feel that they have the responsibility to satisfy their online friends' needs that require some form of support and assistance (e.g. Could you give a thumbs up to my post?), and provide emotional or material support for the counterpart [14]. When individuals are facing an increasing number of social support requests than they can supply, they are likely to become exhausted and feel uncomfortable to provide too much social support, resulting in a state of being socially overload [21]. Once the amount of social requests online exceed users' coping capability, this social condition becomes a troublesome environmental stimulus that causes a series of emotional and behavioral reactions [22]. This unhealthy state has been empirically verified as a stressor that causes negative impacts on individuals' lives [21]. Hence, social overload, combined with information overload and communication overload, serve as three dimensions of overload associated with excessive social media use in our study.

\subsection{Technostress and exhaustion as strains}

We focus on two psychological strains examined in this study, technostress and exhaustion, which are individual psychological states of mind that possess the potential for influencing behavioral outcomes through cognitive biases. The choice of these two strains lies in both the recently increased attention and construct development of each within the IT literature [23-25].

In IT research, technostress refers to the stress derived from the use of information technology [16]. Such stress can be caused by various conditions such as information overload and communication overload [26, 27]. The explosive growth of social media platforms and mobile technologies promotes the severity of technostress [28]. [29] empirically demonstrated that technostress can reduce end-user performance. The negative effect of technostress on university students' academic performance might appear through the loss of focus and enhancing stress levels [30]. Students may experience situations of being overload and create perception of getting stressed induced by the overuse of social media. This kind of stress can be called as social media-induced technostress. In this study, we define technostress as an individual's experience of stress when using social media, which is caused by techno-stressors $[16,31]$.

Exhaustion has been widely investigated in previous research as a particular type of psychological strain caused by overload $[14,32]$. In social media environment, the overburdened amount of information and interaction in social media platform can impair users vigor and make them feel exhausted [21]. Exhaustion refers to a state of extreme tiredness after a long-term involvement in demanding situations with a large amount of mental resources consumption [33]. As the psychological response of stressors, [10] investigated social networking service (SNS) exhaustion as an outcome of social overload in the SNS context. [6] investigated work overload as the strongest predictor of employees' work exhaustion. In our context, exhaustion refers to individual's aversive, potentially harmful, and unconscious psychological response to stressful conditions when using social media [21], which represents an exhausted feeling from social media usage.

\subsection{Academic performance as outcome}

In educational environment, the relationship between social media use and academic performance has been the research focus in recent years. [34] and [35] believed that the use of social media can facilitate learning processes including knowledge sharing and problem solving, and improve academic performance. While [36] found a significant negative relationship between SNS-use and academic performance based on the meta-analysis. [37] also found that compulsive social media use can predict problematic learning outcomes. In this study, excessive social media use may create unwanted outcomes. Students' academic performance can be affected because of the insufficient time and energy on learning. Decreased academic performance is thereby a critical behavioral outcome to the stressful conditions from using social media in school context.

\section{Research model}

We constructed our research model based on the $\mathrm{S}-\mathrm{S}-\mathrm{O}$ model and relevant theories discussed above (Figure 1). Evidence from previous literature shows that gender and use experience have the potential to affect 
students' usage behavior, we thus include these two variables as control variables.

\subsection{Overload, technostress, and exhaustion}

3.1.1 Information overload. Social media offers students various kinds of platforms to receive huge amount of information. Nevertheless, the capability to deal with information is limited for an individual. With an influx of vast information comes an influx of disorder. Individuals are likely to produce a sense of confusion and suffer from the feeling of stress when facing too much information [15]. Indeed, similar associations between information overload and stress have been found in prior studies. For example, [38] demonstrated that higher levels of cyber information overload positively related to greater stress. Thus,

H1a. Information overload has a positive effect on technostress.

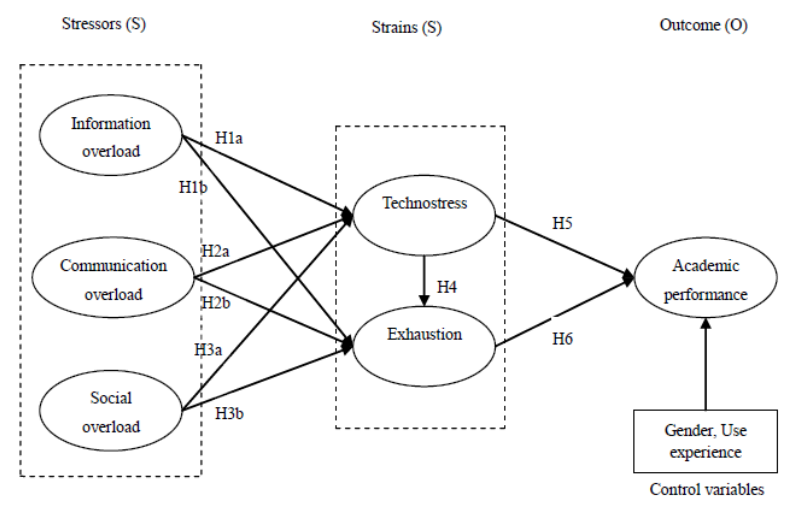

Figure 1. Model with related hypotheses

As social media continues to penetrate into students' lives, they are receiving, producing as well as spreading information at an unprecedented rate. When the amount of information exceeds an individual's ability to process effectively, information overload is very likely to occur, which may result in negative emotions and states [16]. Particularly, psycho-cognitive limits can be a serious issue induced by information overload, and students who suffer from cognitive limits tend to have a tired and exhausted feeling. Research carried out by [3] indicated that there is a connection between information overload and social network fatigue. We then hypothesize the following:

H1b. Information overload has a positive effect on exhaustion.

3.1.2. Communication overload. To better "keep in touch" with friends in social media, students have to check social media constantly to ensure that messages are not missed and replies can be made as quickly as possible. This frequent communication may affect students' cognitive capacities, leading to cognitive burden. Such cognitive burden gets students involved in stress created by social media. Users who suffer from communication overload may fall into stressful states of having to participate in too many communication activities online [3]. Therefore,

H2a. Communication overload has a positive effect on technostress.

Feeling unable to deal with excessive communication tasks may trigger exhaustion for social media users [15]. The communication requests produced by social media make people difficult to focus on their current work, and energy for completing work tasks is consumed because of these communication distractions. Research has shown that once interrupted, workers need at least eleven minutes to return to the original work state [39]. As for university students, communication requests from numerous social media devices are interruptive during studying hours, which may increase difficulties for them to concentration on their school work and drive them exhausted [3]. Therefore,

H2b. Communication overload has a positive effect on exhaustion.

3.1.3. Social overload. When using social media, users are likely to spend a huge amount of time and energy than they expect because of various unnecessary social connections, activities and requests embedded in this large social network. When users are socially overload, they may perceive some negative experience of using social media, such as job burnout [7] and fatigue [40]. Such negative experience, combined with excessive social support demands, make users under a stressful situation, leading to technostress. Thus, we propose that: H3a. Social overload has a positive effect on technostress.

Although the expand of social media allows users to interact with others without the boundaries of time and location, exposure to these social interactions makes users exhausted when they feel uncomfortable to respond to too many social requests. As explained by [21], social overload reflects users' feeling of "providing too much social support to others", which can cause the exhausted feeling of excessive social connections. Thus, it can be inferred that social overload positively impact users' feeling of exhaustion. Therefore, we propose that:

H3b. Social overload has a positive effect on exhaustion. 


\subsection{Technostress, exhaustion, and academic performance}

Exhaustion means users' aversive and potentially harmful psychological reaction to stressful situations, describing their feeling of being tired of activities when using IT [21]. Therefore, it is rational to infer that one critical result of technostress is the feeling of exhaustion. We thereby assume that technostress induces exhaustion, and it explains why more and more users feel exhausted while using social media. Therefore,

H4. Technostress has a positive effect on exhaustion.

Technostress requires more energy to deal with social media, potentially taking away time from students' leaning tasks necessary for achieving better academic performance. Students with technostress are likely to be unable to respond appropriately to leaning requirements, because it is difficult to obtain a balance between technology usage and study. Thus,

H5. Technostress has a negative effect on academic performance.

With the continuous penetration of social media, an increasing number of people feel that they are facing more information and social requests than they expect. Users have to spend a lot of energy on social media and thus become exhausted. In the organizational behavior field, work exhaustion has been found to negatively impact employees' productivity, organizational commitment, and job satisfaction [41]. In educational context, we infer that exhaustion impair students' academic performance because they cannot concentrate their energies on leaning. Therefore,

H6. Exhaustion has a negative effect on academic performance.

\section{Research methodology}

\subsection{Sample and data collection}

Given that this study investigated the effects of excessive social media usage behavior in educational environment, the target population was composed of students in Chinese universities. Through published advertisements on five Chinese universities' bulletin board system (BBS), 573 undergraduate students were invited to participate in our survey. We sent survey invitations to participants via Email enclosed with a link to an online questionnaire. The Email started with a note informing that this survey is completely anonymous and all data will only be used for academic research. Two weeks later, a second Email was sent to encourage participation and facilitate the procedure of data collection. After finishing the online questionnaire, a red packet containing 10 yuan (approximately 1.52 dollars) was sent to the WeChat account of each respondent. The whole data collection period lasted one month in October, 2017. At last, a total number of 253 students completed the survey, indicating a response rate of $44.15 \%$. After eliminating 4 participants who reported to hardly use social media, the remaining 249 respondents were considered as valid samples for investigation. Among the respondents, $43.8 \%$ were males and $56.2 \%$ were females; the mean age was 20.4; the proportion of freshman, sophomore, junior, and senior were $16.9 \%$, $24.5 \%, 26.9 \%$, and $31.7 \%$, respectively; and $88.0 \%$ had over four years of social media use experience.

\subsection{Measurement}

Our study adopted 5-point Likert scales to measure all the variables, ranging from 1 (strongly disagree) to 5 (strongly agree). The measurement items are presented in Appendix A. We relied on existing literatures in measurement development because they are well-established and highly reliable. Items for measuring information overload, communication overload and social overload were adapted from [5], [42] and [21], respectively. Technostress was evaluated by using 6 items adapted from [16] and modified to fit the context of social media use, whereas exhaustion included 3 items from the recent study of [21]. In terms of academic performance, we used items developed by [4] to capture university students' self-reported academic performance. Moreover, gender and use experience (years of using social media) were selected as control variables to observe if there is any influence of personal characteristics.

\section{Data analysis}

We adopted a Partial Least Square (PLS) technique--SmartPLS to evaluate the proposed model because of fewer constraints of statistical distribution and convenience for theory exploration compared with covariance-based structural equation modeling (SEM) $[43,44]$. Measurement model and structural model were both assessed following a two-step procedure.

\subsection{Measurement model}

Reliability was assessed by comparing the values of Cronbach's alpha and composite reliability (CR). As shown in Table 1, the values of Cronbach's alpha $(\alpha)$ of 
all constructs range from 0.72 to 0.90 and the values of CR exceed 0.80 , which meet the threshold value of 0.70 $[45,46]$, confirming adequate reliability of measures.

As suggested by [45] and [47], convergent validity is considered acceptable when: (1) item loadings exceed 0.70 ; (2) average variance extracted (AVE) values exceed 0.50 ; (3) CR values are equal to or above 0.70 . As shown in Table 1, except that items CO1 and $\mathrm{CO} 2$ load lower than 0.70 (above 0.60 ), other items' loadings are greater than 0.70 . The minimum value of AVE is 0.58 , indicating that AVE values meet the recommended level. Also, the values of CR are all higher than 0.70 . Thus, convergent validity was established by these three criteria.

The square roots of AVE and correlations were adopted to test discriminant validity [45]. Table 2 shows that each construct's square root of AVE displayed in the diagonal is higher than the correlations in the row and column that correspond to that construct, providing evidence for discriminant validity.

Table 1. Psychometric properties of instruments

\begin{tabular}{|c|c|c|c|c|}
\hline Factor & Item & $\begin{array}{c}\text { Mean } \\
\text { (Std.Dev) }\end{array}$ & Loading & $\alpha$ \\
\hline \multirow{3}{*}{$\begin{array}{c}\text { Information } \\
\text { overload } \\
(\mathrm{CR}=0.83 \text {, } \\
\mathrm{AVE}=0.63)\end{array}$} & IO1 & $3.67(1.03)$ & 0.70 & \multirow{3}{*}{0.72} \\
\hline & $\mathrm{IO} 2$ & $2.64(1.06)$ & 0.88 & \\
\hline & IO3 & $3.12(1.03)$ & 0.79 & \\
\hline \multirow{4}{*}{$\begin{array}{c}\text { Communication } \\
\text { overload } \\
(\mathrm{CR}=0.84, \\
\mathrm{AVE}=0.58)\end{array}$} & $\mathrm{CO} 1$ & $3.00(1.09)$ & 0.61 & \multirow{4}{*}{0.76} \\
\hline & $\mathrm{CO} 2$ & $3.48(1.14)$ & 0.69 & \\
\hline & $\mathrm{CO} 3$ & $2.80(1.09)$ & 0.88 & \\
\hline & $\mathrm{CO} 4$ & $2.95(1.08)$ & 0.82 & \\
\hline \multirow{5}{*}{$\begin{array}{l}\text { Social overload } \\
\qquad(\mathrm{CR}=0.91 \\
\mathrm{AVE}=0.68)\end{array}$} & SO1 & $2.74(1.04)$ & 0.81 & \multirow{5}{*}{0.88} \\
\hline & $\mathrm{SO} 2$ & $3.00(1.06)$ & 0.80 & \\
\hline & $\mathrm{SO} 3$ & $2.63(1.07)$ & 0.82 & \\
\hline & $\mathrm{SO} 4$ & $2.83(1.10)$ & 0.85 & \\
\hline & SO5 & $3.02(1.12)$ & 0.84 & \\
\hline \multirow{6}{*}{$\begin{array}{l}\text { Technostress } \\
(\mathrm{CR}=0.91 \\
\mathrm{AVE}=0.63)\end{array}$} & TS1 & $2.49(1.04)$ & 0.81 & \multirow{6}{*}{0.88} \\
\hline & TS2 & $2.76(1.11)$ & 0.83 & \\
\hline & TS3 & $2.80(1.16)$ & 0.81 & \\
\hline & TS4 & $2.87(1.11)$ & 0.79 & \\
\hline & TS5 & $2.84(1.11)$ & 0.79 & \\
\hline & TS6 & $2.78(1.14)$ & 0.74 & \\
\hline \multirow{3}{*}{$\begin{array}{l}\text { Exhaustion } \\
(\mathrm{CR}=0.93, \\
\mathrm{AVE}=0.77)\end{array}$} & EX1 & $2.74(1.08)$ & 0.91 & \multirow{3}{*}{0.88} \\
\hline & EX2 & $2.81(1.00)$ & 0.90 & \\
\hline & EX3 & $2.63(1.02)$ & 0.89 & \\
\hline \multirow{2}{*}{$\begin{array}{c}\text { Academic } \\
\text { performance }\end{array}$} & AP1 & $3.58(0.97)$ & 0.86 & \multirow{2}{*}{0.90} \\
\hline & $\mathrm{AP} 2$ & $3.50(0.97)$ & 0.90 & \\
\hline
\end{tabular}

\begin{tabular}{rlll}
\hline$(\mathrm{CR}=0.93$, & $\mathrm{AP} 3$ & $3.55(0.98)$ & 0.88 \\
$\mathrm{AVE}=0.77)$ & $\mathrm{AP} 4$ & $3.64(1.00)$ & 0.88 \\
\hline
\end{tabular}

Table 2. Correlations and square roots of AVE

\begin{tabular}{lllllll}
\hline Factor & IO & CO & SO & TS & EX & AP \\
\hline IO & $\mathbf{0 . 7 9}$ & & & & & \\
CO & 0.62 & $\mathbf{0 . 7 6}$ & & & & \\
SO & 0.33 & 0.36 & $\mathbf{0 . 8 2}$ & & & \\
TS & 0.48 & 0.51 & 0.43 & $\mathbf{0 . 8 0}$ & & \\
EX & 0.48 & 0.41 & 0.32 & 0.68 & $\mathbf{0 . 9 0}$ & \\
AP & -0.23 & -0.18 & -0.24 & -0.36 & -0.35 & $\mathbf{0 . 8 8}$ \\
\hline
\end{tabular}

In addition, considering that all the data were self-reported answers from the same respondent, Harman's single-factor test was conducted to measure the potential threat of common method bias [48]. The result showed that no single factor was found to be able to explain most of the variance, in which the most significant factor explained only $31.7 \%$ of the variance, implying that common method bias does not have a serious impact on the result of this study. Due to the imperfection of Harman's single-factor test, correlation matrix was presented as a complementary evidence for common method bias assessment. In Table 2, no extremely high correlation ( $r>0.90)$ [49] was observed. Hence, the threat of common method bias can be excluded.

\subsection{Structural model}

The results of PLS test of structural model are presented in Figure 2. In general, most hypotheses are significant, revealing the essential impact of social media-induced overload on university students' academic performance. Specifically, information overload has direct positive relationships with technostress and social media exhaustion. Both communication overload and social overload positively impact technostress, whereas their relationships with exhaustion are not supported. The significant path coefficient of technostress to exhaustion indicates strong connection between the two constructs. In strain-outcome paradigm, both technostress and exhaustion lead to decreased academic performance of university student users. As for control variables, both gender and use experience show no significant impacts on the dependent variable. Finally, $16 \%$ variance of academic performance is explained.

By following a three-step procedure suggested by Baron [50], we further tested the mediation effects of 
technostress and exhaustion. First, technostress served as a fully mediator in the relationships among three types of overload and academic performance. Second, exhaustion fully mediated the connections among information overload, communication overload and academic performance, while partially mediated the relationship between social overload and academic performance. Third, technostress partially mediated the relationship between information overload and exhaustion, but fully mediated the effects of communication overload and social overload on exhaustion.

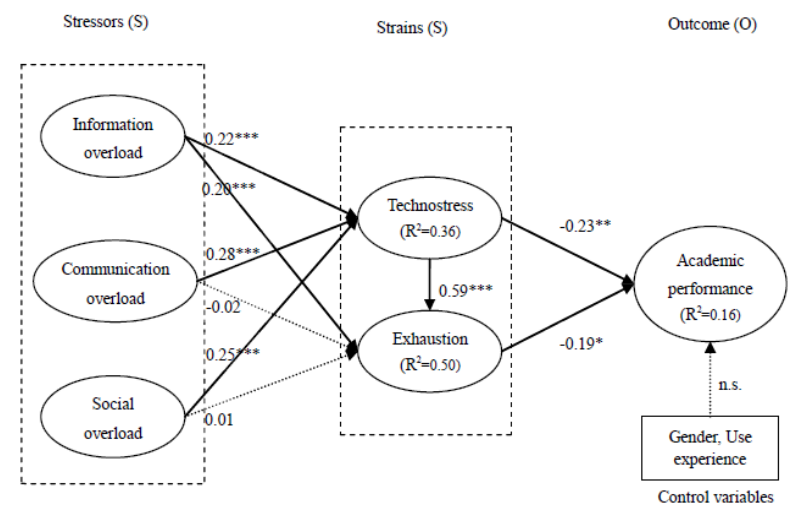

Figure 2. PLS results of the structural model ${ }^{*} p<0.05$; ${ }^{* * *} p<0.01 ;{ }^{* * *} p<0.001$.

\section{Discussion and conclusions}

\subsection{Key findings}

By applying the S-S-O model, this study explored the adverse outcomes of excessive social media use on university students and investigated the impact of overload on their academic performance. Our results reveal several important findings.

First, all three dimensions of social media-related overload (i.e., information overload, communication overload, and social overload) are significant determinants of technostress. This finding supplements with the research of [28], which suggested that overdependence on smartphones is related to compulsive usage and can cause technostress. It indicates that overloads from excessive social media usage are important stressors influencing university students' technostress. The result improves our understanding of the effects of overload due to excessive social media usage on university students' technostress.

Second, as opposed to the result that information overload has significantly positive impact on exhaustion, the influences of communication overload and social overload on exhaustion are not significant as expected. It reveals that communication and social support response requiring less cognitive resources than information process. This is partially consistent with the findings of previous studies on social networking sites $[3,15,21]$ that all information overload, communication overload, and social overload have significant effects on SNS fatigue and exhaustion. This may occur when students choose to reduce the communication and social requests in daily lives due to the autonomy in social media use, such as filtering unnecessary requests, or sending posts or information to several targeted friends. Therefore, students with richer experience in processing communication and social requests may have less exhaustion risks. Additionally, mediating analysis indicates that communication and social overloads still have indirect effects on exhaustion through technostress.

Third, both technostress and exhaustion can negatively influence university students' academic performance. This is in line with the extant research [13, 24], which indicates that psychological strains, technostress and exhaustion, are vital factors in influencing performance in organizational environment. When technostress occurs, students may not be able to concentrate on their school work as the level of technostress increases, resulting in decreased academic performance. In addition, exhausted students may not have sufficient resources to accomplish work via social media, which in turn lead to lowering academic performance.

\subsection{Theoretical implications}

The theoretical implications of this study are presented as following. First, unlike prior studies concentrating on the positive effect of social media in an academic setting [51], this study extends the research on the negative effects of social media usage among university students. As the level of usage increases, social media can produce unintended consequences such as overload, technostress, and decreased academic performance, which need to be systematically investigated in order to get balanced perspectives of social media [3] from a pedagogical perspective. In addition, this study is conducted in China, which has typical characteristics including collectivism and guanxi culture that influence students' social media usage behavior. This also enriches social media research in educational environment that has been investigated in other countries, such as Kuwait [37], Brazil [52], and Italy [53].

Second, our study reveals the underlying mechanism of how overload from excessive social media usage affect students' academic performance. Based on the 
S-S-O paradigm, a research model was constructed to empirically investigate the different impacts of three kinds of overload on technostress and exhaustion, which in turn induce poor academic performance. It can help both researchers and educators understand and identify the negative outcomes of social media use in school environment in a more coherent and comprehensive way, and enrich the literature of dark side of social media usage.

Third, this study also advances our understanding of irrational usage of social media by identifying a more comprehensive classification of social media-induced stressors in terms of perceived overload associated with informational, communicational, and social aspects of social media. Our study generalizes the research on overload to the educational context, and emphasizes the role of social overload as a social media-specific stressor in creating the adverse effect on psychological reaction [21].

\subsection{Practical implications}

This study provides several practical implications. First, although university students today are extensively using social media, the negative consequences of excessive usage of social media should not be ignored. By identifying the role of overload, students are able to recognize their problematic use behaviors to alleviate the negative consequences brought by social media use. For example, students can change the visibility settings on friends' postings, or quit some unnecessary online social networks, to reduce unexpected online social activities. They can also reduce time and energy on social media through delayed response and centralized reply.

Second, colleges and universities should provide coping strategies to regulate students' social media usage behavior and reduce the negative impacts of excessive social media use. For instance, organizations can offer stress-management countermeasures to help students identify stressful situations and better utilize social media and information technologies [54]. They can also educate students to enhance their IT mindfulness, which can effectively alleviate technostress conditions and improve performance [55].

\subsection{Limitations and future research}

Despite the useful implications of our study, there are still several limitations that need to be acknowledged. First, the context of this study is educational environment in China. Thus the generalizability of our study is limited. Future research may consider more comprehensive samples to improve the robustness of our conclusion. Second, we only focus on overload in understanding the influencing mechanism of excessive social media use. The stimuli encountered by individuals in the case of technostress are notably complex; the other stressors, such as conflict and invasion $[9,56]$, can also influence subsequent strain and academic performance. Future research may consider other stimuli in social media environment and test their different impacts. Finally, we collect cross-sectional data to investigate students' social media usage behavior, which do not testify the causality of the model. A longitudinal research design is necessary in future investigation.

\section{Appendix A. Measures of constructs}

\begin{tabular}{l} 
Information Overload \\
\hline IO1: I am often distracted by the excessive amount of \\
information in social media. \\
IO2: I am overwhelmed by the amount of information that I \\
process on a daily basis from social media. \\
IO3: I feel some problems with too much information in \\
social media to synthesize instead of not having enough \\
information. \\
\hline Communication Overload \\
\hline CO1: I feel that I generally receive too many notifications \\
on new postings, push messages, and news feeds, among \\
others from social media as I perform other tasks. \\
CO2: I often feel overloaded with social media \\
communication. \\
CO3: I receive more communication messages and news \\
from friends on social media than I can process. \\
CO4: I receive more communication messages and news \\
from friends on social media than I can process. \\
\hline Social Overload \\
\hline SO1: I take too much care of the well-being of my friends \\
on social media. \\
SO2: I deal with my friends' problems on social media too \\
much. \\
SO3: My sense of responsibility for how much fun my \\
friends have on social media is too strong. \\
SO4: I care for my friends on social media too often. \\
SO5: I pay too much attention to my friends' posts on \\
social media. \\
\hline Technostress \\
TS1: I am forced by social media to live very tight time \\
schedules. \\
TS2: I am forced to change habits to adapt to new \\
developments on social media. \\
TS3: I have to sacrifice my personal time to keep current \\
on new social media updates. \\
TS4: I feel my personal life is being invaded by social \\
media. \\
TS5: I do not find enough time to study and upgrade my \\
technology skills on social media. \\
Exhaustion \\
\end{tabular}


EX1: I feel drained from activities that require me to use social media.

EX2: I feel tired from my social media activities.

EX3: Using social media is a strain for me.

\section{Academic Performance}

AP1: I am confident about the adequacy of my academic skills and abilities.

AP2: I feel competent conducting my course assignments. AP3: I have learned how to successfully perform my coursework in an efficient manner.

AP4: I have performed academically as well as I anticipated I would.

\section{References}

[1] C. Wang, M.K. Lee, Z. Hua, "A theory of social media dependence: Evidence from microblog users", Decision Support Systems, 69 (2015) 40-49.

[2] J.R. Edwards, C.L. Cooper, "The person-environment fit approach to stress: recurring problems and some suggested solutions", Journal of Organizational Behavior, 11 (1990) 293-307.

[3] A.R. Lee, S.-M. Son, K.K. Kim, "Information and communication technology overload and social networking service fatigue: A stress perspective", Computers in Human Behavior, 55 (2016) 51-61.

[4] A.Y. Yu, S.W. Tian, D. Vogel, R.C.-W. Kwok, "Can learning be virtually boosted? An investigation of online social networking impacts", Computers \& Education, 55 (2010) 1494-1503.

[5] P. Karr-Wisniewski, Y. Lu, "When more is too much: Operationalizing technology overload and exploring its impact on knowledge worker productivity", Computers in Human Behavior, 26 (2010) 1061-1072.

[6] J.E. Moore, "One road to turnover: An examination of work exhaustion in technology professionals", MIS Quarterly, 24 (2000) 141-168.

[7] F. Gaudioso, O. Turel, C. Galimberti, "The mediating roles of strain facets and coping strategies in translating techno-stressors into adverse job outcomes", Computers in Human Behavior, 69 (2017) 189-196.

[8] G.F. Koeske, R.D. Koeske, "A preliminary test of a stress-strain-outcome model for reconceptualizing the burnout phenomenon", Journal of Social Service Research, 17 (1993) 107-135.

[9] R. Ayyagari, V. Grover, R. Purvis, "Technostress: technological antecedents and implications", MIS Quarterly, 35 (2011) 831-858.

[10] C. Maier, S. Laumer, C. Weinert, T. Weitzel, "The effects of technostress and switching stress on discontinued use of social networking services: a study of Facebook use", Information Systems Journal, 25 (2015) 275-308.

[11] E. Bucher, C. Fieseler, A. Suphan, "The stress potential of social media in the workplace", Information, Communication \& Society, 16 (2013) 1639-1667.

[12] F. Cheung, C. Tang, "The influence of emotional dissonance on subjective health and job satisfaction: Testing the stress-strain-outcome model", Journal of Applied Social Psychology, 40 (2010) 3192-3217.
[13] C.H. Choi, T.T. Kim, G. Lee, S.K. Lee, "Testing the stressor-strain-outcome model of customer-related social stressors in predicting emotional exhaustion, customer orientation and service recovery performance", International Journal of Hospitality Management, 36 (2014) 272-285.

[14] C. Maier, S. Laumer, A. Eckhardt, T. Weitzel, "When social networking turns to social overload: Explaining the stress, emotional exhaustion, and quitting behavior from social network sites' users ", In Proceedings of European Conference on Information Systems, (2012).

[15] S. Zhang, L. Zhao, Y. Lu, J. Yang, "Do you get tired of socializing? An empirical explanation of discontinuous usage behaviour in social network services", Information \& Management, 53 (2016) 904-914.

[16] T. Ragu-Nathan, M. Tarafdar, B.S. Ragu-Nathan, Q. Tu, "The consequences of technostress for end users in organizations: Conceptual development and empirical validation", Information Systems Research, 19 (2008) 417-433.

[17] T.T. Kim, S. Paek, C.H. Choi, G. Lee, "Frontline service employees' customer-related social stressors, emotional exhaustion, and service recovery performance: customer orientation as a moderator", Service Business, 6 (2012) 503-526.

[18] R. Larose, R. Connolly, H. Lee, K. Li, K. Hales, "Connection overload? A cross cultural study of the consequences of social media connection", Information Systems Management, 31 (2014) 59-73.

[19] M. Van Volkom, J.C. Stapley, V. Amaturo, "Revisiting the digital divide: generational differences in technology use in everyday life", North American Journal of Psychology, 16 (2014) 557.

[20] P.A. Kirschner, A.C. Karpinski, "Facebook® and academic performance", Computers in Human Behavior, 26 (2010) 1237-1245.

[21] C. Maier, S. Laumer, A. Eckhardt, T. Weitzel, "Giving too much social support: social overload on social networking sites", European Journal of Information Systems, 24 (2015) 447-464.

[22] G.W. Evans, E. Rhee, C. Forbes, K.M. Allen, S.J. Lepore, "The meaning and efficacy of social withdrawal as a strategy for coping with chronic residential crowding", Journal of Environmental Psychology, 20 (2000) 335-342.

[23] Z.R. Steelman, A.A. Soror, "Why do you keep doing that? The biasing effects of mental states on IT continued usage intentions", Computers in Human Behavior, 73 (2017) 209-223.

[24] S. Brooks, C. Califf, "Social media-induced technostress: Its impact on the job performance of it professionals and the moderating role of job characteristics", Computer Networks, 114 (2017) 143-153.

[25] I. Mahmud, T. Ramayah, S. Kurnia, "To use or not to use: Modelling end user grumbling as user resistance in pre-implementation stage of enterprise resource planning system", Information Systems, 69 (2017) 164-179.

[26] R. Ayyagari, "Impact of information overload and task-technology fit on technostress", In Proceedings of the Southern Association for Information Systems Conference, (2012). 
[27] M. Tarafdar, Q. Tu, B.S. Ragu-Nathan, T. Ragu-Nathan, "The impact of technostress on role stress and productivity", Journal of Management Information Systems, 24 (2007) 301-328.

[28] Y.-K. Lee, C.-T. Chang, Y. Lin, Z.-H. Cheng, "The dark side of smartphone usage: Psychological traits, compulsive behavior and technostress", Computers in Human Behavior, 31 (2014) 373-383.

[29] M. Tarafdar, Q. Tu, T. Ragu-Nathan, "Impact of technostress on end-user satisfaction and performance", Journal of Management Information Systems, 27 (2010) 303-334.

[30] K.-L. Hsiao, Y. Shu, T.-C. Huang, "Exploring the effect of compulsive social app usage on technostress and academic performance: Perspectives from personality traits", Telematics and Informatics, 34 (2017) 679-690.

[31] X. Zheng, M.K.O. Lee, "Excessive use of mobile social networking sites: Negative consequences on individuals", Computers in Human Behavior, 65 (2016) 65-76.

[32] M.K. Ahuja, K.M. Chudoba, C.J. Kacmar, D.H. McKnight, J.F. George, "IT road warriors: Balancing work-family conflict, job autonomy, and work overload to mitigate turnover intentions", MIS Quarterly, 31 (2007) 1-17. [33] W. Schaufeli, M. Leiter, R. Kalimo, "The general burnout inventory: A self-report questionnaire to assess burnout at the workplace", Work, Stress and Health, (1995) 14-16.

[34] C. Lampe, D.Y. Wohn, J. Vitak, N.B. Ellison, R. Wash, "Student use of Facebook for organizing collaborative classroom activities", International Journal of Computer-Supported Collaborative Learning, 6 (2011) 329-347.

[35] A. Krasilnikova, A. Smirnova, "Online social adaptation of first-year students and their academic performance", Computers \& Education, 113 (2017) 327-338.

[36] D. Liu, P.A. Kirschner, A.C. Karpinski, "A meta-analysis of the relationship of academic performance and Social Network Site use among adolescents and young adults", Computers in Human Behavior, 77 (2017) 148-157.

[37] A.M. Aladwani, M. Almarzouq, "Understanding compulsive social media use: The premise of complementing self-conceptions mismatch with technology", Computers in Human Behavior, 60 (2016) 575-581.

[38] S. Misra, D. Stokols, "Psychological and health outcomes of perceived information overload", Environment and Behavior, 44 (2012) 737-759.

[39] C.X.J. Ou, R.M. Davison, "Interactive or interruptive? Instant messaging at work", Decision Support Systems, 52 (2011) 61-72.

[40] A. Dhir, Y. Yossatorn, P. Kaur, S. Chen, "Online social media fatigue and psychological wellbeing-A study of compulsive use, fear of missing out, fatigue, anxiety and depression", International Journal of Information Management, 40 (2018) 141-152.

[41] B.W. Swider, R.D. Zimmerman, "Born to burnout: A meta-analytic path model of personality, job burnout, and work outcomes", Journal of Vocational Behavior, 76 (2010) 487-506.

[42] J. Cho, D.I. Ramgolam, K.M. Schaefer, A.N. Sandlin, "The rate and delay in overload: An investigation of communication overload and channel synchronicity on identification and job satisfaction", Journal of Applied Communication Research, 39 (2011) 38-54.

[43] C.W. Wynne, "Issues and opinion on structural equation modelling", MIS Quarterly, 22 (1998) 1-8.

[44] G. Bassellier, I. Benbasat, "Business competence of information technology professionals: Conceptual development and influence on IT-business partnerships", MIS Quarterly, 28 (2004) 673-694.

[45] C. Fornell, D.F. Larcker, "Evaluating structural equation models with unobservable variables and measurement error", Journal of Marketing Research, 18 (1981) 39-50.

[46] J.C. Nunnally, "Psychometric theory", American Educational Research Journal, 5 (1994) 83.

[47] J.F. Hair Jr, G.T.M. Hult, C. Ringle, M. Sarstedt, A primer on partial least squares structural equation modeling (PLS-SEM), Sage Publications, (2016).

[48] P.M. Podsakoff, S.B. MacKenzie, J.-Y. Lee, N.P. Podsakoff, "Common method biases in behavioral research: A critical review of the literature and recommended remedies", Journal of Applied Psychology, 88 (2003) 879.

[49] P.A. Pavlou, H. Liang, Y. Xue, "Understanding and mitigating uncertainty in online exchange relationships: A principal--agent perspective", MIS Quarterly, 31 (2007) 105-136.

[50] R.M. Baron, D.A. Kenny, "The moderator-mediator variable distinction in social psychological research: Conceptual, strategic, and statistical considerations.", Journal of Personality and Social Psychology, 51 (1986) 1173-1182. [51] I. Jahnke, P. Bergström, E. Mårell-Olsson, L. Häll, S. Kumar, "Digital Didactical Designs as research framework: iPad integration in Nordic schools", Computers \& Education, 113 (2017) 1-15.

[52] D.D. Felisoni, A.S. Godoi, "Cell phone usage and academic performance: An experiment", Comput Educ, 117 (2018) 175-187.

[53] F. Giunchiglia, M. Zeni, E. Gobbi, E. Bignotti, I. Bison, "Mobile social media usage and academic performance", Computers in Human Behavior, 82 (2018) 177-185.

[54] R. Jena, "Technostress in ICT enabled collaborative learning environment: An empirical study among Indian academician", Computers in Human Behavior, 51 (2015) 1116-1123.

[55] A. Ioannou, A. Papazafeiropoulou, "Using IT mindfulness to mitigate the negative consequences of technostress", In Proceedings of Americas Conference on Information Systems, (2017).

[56] A. Suh, A. Suh, J. Lee, J. Lee, "Understanding teleworkers' technostress and its influence on job satisfaction", Internet Research, 27 (2017) 140-159. 